\title{
THE APPROACHING EXTINCTION OF THE MAYFLOWER DESCENDANTS
}

\author{
We Are Soon to Celebrate the 300th Anniversary of the Landing of the Pilgrims. \\ If Their Present Birth Rate Continues for Another 300 Years, \\ It Will Be Possible to Put All the Surviving Descendants \\ Back Again Into the Mayflower, and \\ No Overcrowding \\ S. J. Hormes and C. M. Doud \\ University of California, Berkeley, Cal.
}

\section{1} HE data upon which this paper is based were obtained partly from a biographical study of Mayflower families, and partly from the results of a questionnaire sent to the members of the California branch of the Society of Mayflower Descendants. We are indebted to $\mathrm{Mr}$. Herbert Folger, the historian of the California branch of this society, for a list of the names and addresses of members and for his kindly interest in our work. We wish also to thank the numerous Mayflower descendants who have taken the trouble to answer the questionnaire sent to them.

The questionnaires were furnished with spaces for filling in the desired data, which included the ages of husband and wife, date of marriage, number of children, including those stillborn, the number of children in the family of the father and mother of the Mayflower descendants, and a query concerning what may have seemed to many a mere matter of idle curiositythe religion of both husband and wife. Data were also requested concerning the dates of marriage and number of children of any descendants of the present members.

The statement of religious affiliation was requested with a view of ascertaining what correlation might exist between the religious belief of parents and the size of their family. Families are unusually large in certain sects, such as Catholics and Jews, but our data were not sufficient to enable us to draw any conclusion as to the correlation. between religion and fecundity in the group of people investigated.

Of the 241 questionnaires sent out. 116 were returned, but 10 of these were imperfectly filled out, so that they could not be used. Records were obtained sufficiently complete for our purpose from 106 families. It is hardly probable that incompleteness of returns would introduce any qualitative differences of importance in the data. Those having no children might be somewhat less apt to fill out and return the blanks; if so, the reduction in the size of the family would be somewhat greater than our records indicate.

We have grouped families according to the date of the birth of the parents. Most of our data concerns individuals born in the two 20-year intervals, 18401860 and 1860-1880. There are fewer records of the families of individuals born between 1820 and 1840 , but these show a considerably higher birth rate than the families belonging to subsequent decades. The families of individuals born after 1880 cannot be considered complete, since more children may be born in them. Parents, both of whom were born between 1860 and 1880, may, in rare cases, produce more children, 
but not enough to sensibly influence results. The youngest woman in this age group would be 38 years of age. There are, as a matter of fact, only eight women in this group under 45 years of age, and judging from the children born between the ages of 38 and 45 in our group, the additions to the race from this source will doubtless be very few. We have made separate tabulations of the number of children of parents, both of whom were born in the second half of this interval, i. e., 1870 to 1880 , and it shows the startlingly low record of only $15 / 10$ children per family.

\section{DECLINE IS STEADY}

The general decline in the size of the families of the Mayflower descendants is clearly indicated by the table (see appendix). The first horizontal column includes the number of children in the families of the Mayflower descendants to whom questionnaires were addressed. It shows that the decrease in the size of the family has gone on steadily with the decreasing age of the married couples down to the year 1880 . The families of Mayflower descendants born after this date naturally show a further decrease, but as these families may not in all cases be completed, there is no means of knowing how much of this decrease may be due to a further decline of the birth rate.

In the second horizontal column is listed the number of children in the families of the mothers of the persons addressed, and in the third is a list of the number of children in the father's family. The numbers in both of these columns also show a declining birth rate. In general there are fewer children in the family of the mother than in that of the father. This is doubtless to be attributed to the fact that since mothers are, as the returns show in nearly every case, younger than the fathers, and often several years younger, they belong to rather more recent families than those of their husbands, and, therefore, to families in which the birth rate is more reduced.
It is well known that up to about a half century ago the Mayflower descendants were noteworthy on account of their high fertility, as is indicated by their very rapid increase in a few generations to many times their original number. An examination of the published genealogies of several of the Mayflower families shows the frequent occurrence of 8 to 10 children per family; and even larger families were by no means rare. In order to secure data on the fertility of this stock, before the period covered by our questionnaire, we have tabulated the average number of the children in the genealogy of the Brewster family, which has been compiled by Emma C. Brewster Jones. In this extensive work the data on the various families are grouped under the successive generations which have appeared since the landing of the Pilgrims. It was, therefore, a small task to compute the average size of the families in successive generations. As only those families are listed in which at least one child was born, the data is not strictly comparable to ours, which include sterile unions. Were the latter included, the average size of the families of the Brewster descendants would be somewhat reduced, although childless marriages were formerly less common in this stock than among presentday Mayflower descendants. The data, which were based on the comparison of several hundred families, show clearly the decline of the birth rate during the last three generations. I

In our estimate of the average number of children per family, we have included all the families in the Brewster genealogy up to the eighth generation. For the two subsequent generations, on account of the large number of individuals recorded, we have based our estimate on the first two hundred families of the eighth generation, and the first three hundred of the ninth generation, and we have considered only those cases in which the ages of the parents insure that the family is a completed one. 
The size of the families of the first three generations is obviously of little significance on account of the small number of individuals included. The numbers in the following generation rapidly increased. The fourth generation contains 23 families; the fiftl, 52 ; the sixth, 121 ; the seventh, 275 , showing that the number of fertile unions more than doubled in each generation. About the same rate of increase is shown by counting the total number of children of these families, which are as follows: Thirty in the third, 155 in the fourth, 359 in the fifth, 864 in the sixth, and 1,760 in the seventh generation. The average number of children per family in successive generations is shown in the table (see appendix).

The ninth generation comprises people whose parents lived for the most part in the first half of the nineteenth century. Their birth rate corresponds roughly to that of the parents of existing Mayflower descendants from whom we have received returns from our questionnaires.

\section{DECLINE IS RECENT}

The evidence from the two sources we have considered indicates that the / birth rate has been falling more or less for the last 100 years, but the rate of fall has been more rapid in the latter half of this period. I This is what one would expect in the light of the general decline of the birth rate, especially among people of fairly high social status.

It must be admitted that the members of the Society of Mayflower Descendants represent a more or less selected body of individuals, and that if all the descendants of the original band of Pilgrims were investigated, the average birth rate would be found to be somewhat higher. It is also possible that the birth rate among members of the California branch may be somewhat lower than it is among those residing in other states, but, however this may be, there is little likelihood that the birth rate of the entire group would come near being sufficient to insure the propagation of the stock without loss.

The results we have obtained are quite comparable to those of several other studies on the decline of the birth rate among people of American birth. The average family of the present Mayflower descendant is comparable in size to the families of the graduates of Harvard, Yale, and other universities and colleges, and to the families of American men of science studied by Cattell. These families average somewhere between 2 and $25 / 10$ children per married couple, which is a somewhat better showing than is made by the modern descendants of the Pilgrim Fathers. In fact, the average family of Americanborn parents, judging from all the data that have been collected on the subject, contains somewhat less than three children. With our present birth rate and marriage rate, nearly four children per married couple are required to perpetuate the stock without loss.! It is evident that the people who are of American lineage for more than two generations are not reproducing with sufficient rapidity to rescue their stock from ultimate extinction!

\section{MAYFLOWER'S CAPACITY}

The data we have collected on the birth rate of the Mayflower descendants point to but one conclusion. With the present rate of reproduction there must be going on a rapid diminution in the number of this once rapidly multiplying band. To judge from the evidence in our possession, their rate of multiplication is scarcely one-half what it should be to keep the stock even stationary. This means that four generations would affect a reduction to $1 / 16$ of its present numbers, and that in four more generations there would be only one representative to every 256 at the present time. We shall soon celebrate the 300 th anniversary of the landing of the Pilgrims, but if their present birth rate continues for another 300 years, it would probably be possible to put all the surviving descendants back again into the Mayflower without overcrowd- 


\section{Holmes and Doud: Extinction of Mayflower Descendants 299}

ing the limited capacity of that celebrated vessel.

Considering the role which the Mayflower descendants have played in the history of our nation, this result is certainly one to be greatly deplored. If there is a remedy for this evil it can only become effective, I believe, if the evil is clearly recognized. The consensus of opinion among most of those who have studied the fall of the birth rate is that the chief factor involved is the voluntary restriction of the size of the family. In these days the obligation of obeying the primal behest to be fruitful and multiply, rests very lightly upon most people. I seriously doubt if the majority even of educated poeple have ever thought of how many children per married couple are required to perpetuate the race. How often one may hear it said glibly that one or two children per family is quite enough! Without discussing the probable reasons for this almost incredible ignorance and indifference concerning one of the most important and elementary matters of moral obligation, lit is evident that we need a more widespread appreciation of the dangers of race suicide and a change of attitude in regard to this among people who are the bearers of good inheritance.l Since human beings have come to regulate the matter of their own perpetuation, it is essential that they act with an intelligent appreciation of the racial consequences of their conduct, and not merely from the standpoint of their personal comfort and convenience. The consequence of the reduction in the fecundity of those classes who are successful in reaching a fair educational standard and in attaining a modest degree of financial competence is to recruit the race mainly from ranks below mediocrity. The racial deterioration which would thus be entailed cannot be checked by limiting the propagation of mental defectives. P society in which those with superior inheritance do not perpetuate their stock will eventually suffer racial decay. $i$ Anyone who studies the present condition of the differential birth rate cannot escape the conclusion that this is precisely the condition in which our present generation in America finds itself, and there is no remedy for this situation that does not involve the increase of the birth rate among those of good inheritance, at least to the point necessary to perpetuàte their stock.

It would be a task eminently appropriate for the Society of Mayflower Descendants to consider the problem of the ways and means by which it may rescue itself from extinction. Here is a field for really worthy endeavor, infinitely more valuable than tracing family histories or celebrating the achievements of one's ancestors. It is time now to look to the future rather than to the past. Should the Mayflower descendants succeed, in any degree, towards solving the problem of avoiding extinction, it will not only be a direct service to the country, but one of possibly much greater value through the influence of its example. The problem facing the Mayflower descendants is, of course, the same that, in our modern world, faces people who have risen to a higher social status. It can be solved, I believe, only by the effective dissemination of la sense of racial obligation.l What keeps the population of civilized countries on the increase is a combination of various forces: ignorance, lack of prudence, religion, love of children, the economic value of children, and a sense of racial duty, etc. A stock tends to rise or fall, according to which of these forces predominate. Where ignorance and lack of restraint are the principal causes of differential fecundity, a people tends to be recruited mainly from its inferior strains. Where the higher incentives to fecundity prevail, the race tends to be replenished more from those capable of responding to such motives. The economic value of the child no longer affords a stimulus to family increase, and religion, while still influential in some sects, has largely ceased to make itself effective among Protes- 
tants $^{1}$ and free thinkers. The mass of cultivated people at present persuade themselves that family limitation is a justifiable procedure, especially in a well populated country, but while they may be right in avoiding the burden of the large families of ten or twelve, which were not infrequently found among our Puritan ancestors, they are certainly not justified in carrying the restriction to the present extreme, which, if continued, would effectively dispose of their stock in a few generations. When they thoroughly appreciate this fact, as they do not at the present time, will they respond to the call?

\section{Rehabilitation of Our Wounded}

The United States Government is resolved to do its best to restore every wounded American soldier and sailor to health, strength, and self-supporting activity.

Until his discharge from the hospital all the medical and surgical treatment necessary to restore him to health is under the jurisdiction of the military or naval authorities, according to the branch of the service he is in. The vocational training, the reeducation and rehabilitation necessary to restore him to self-supporting activity, is under the jurisdiction of the Federal Board for Vocational Education.

If he needs an artificial limb or mechanical appliance, the Government will supply it free, will keep it in repair, and renew it when necessary. If, after his discharge, he again needs medical treatment on account of his disability, the
Government will supply it free. While he is in the hospital and while in training afterwards the soldier or sailor will receive compensation as if in service and his family or dependents will receive their allotment.

A wounded soldier or sailor, although his disability does not prevent him from returning to employment without training, can take a course of vocational training free of cost, and the compensation provided by the War Risk Insurance Act will be paid to him and the training will be free, but no allotment will be paid to his family.

Every Liberty Bond holder who holds his bond is keeping up a part of this great work of restoring to health, strength, and usefulness the men who have suffered for their country.-Treasury Department, Bureau of Publicity.

\section{Utah Experiment Station Aids Farmers in War Against Ground Squirrels}

That war is declared against ground squirrels and other rodent pests in Utah is evidenced by the recent appearance of Utah Experiment Station Circular No. 29, "The Control of Rodent Pests," which is being rapidly distributed throughout the State.

The circular was prepared by $\mathrm{Mr}$. Charles J. Sorenson, Instructor in Zoology at the Utah Agricultural College. The publication contains the latest and best methods for killing ground squirrels, pocket gophers, jack rabbits, and field mice, four groups of rodent pests which it is estimated cause an annual loss of not less than $\$ 2,000,000$ to the farm crops of Utah.

Early spring is the best time of all the year in which to wage war against ground squirrels. It is then that the animals emerge from their winter's hibernation, lean and hungry. Their natural food is scarce, and as a consequence the animals will eat poisoned baits more readily than at other times when green food is abundant.

1 See an interesting article by M. Booth on Religious Belief as Affecting the Growth of Population, in the Hibbert Journal, 13, pp. 138-154, 1914. 